\title{
EDITORIAL
}

\section{La instrumentación quirúrgica en el Hospital de San José}

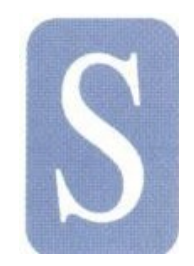
610 hasta mediados del siglo pasado, la instrurnentaci6n quirúrgica comenz6 a desarrollarse como una invaluable ayuda del cirujano durante la realización de los procedimientos quirúrgicos. En Co-

lombia, la historia de la instrumentaci6n como procedimiento independiente, realizado por personal entrenado, comenz6 en 1943 por iniciativa del doctor Juan Di Domenico en el Hospital de San José.

Para conrnemorar los primeros cincuenta años de actividades de instrumentaci6n en el Hospital de San José, se realiz6 una sentida ceremonia de conmemoración el día 27 de octubre de 2001, que reunión va- rias generaciones de instrumentadoras, formadas con programas que han evolucionado para acoplarse a las necesidades sentidas por todos y cada uno de los directivos de la Facultad.

En dicha ocasi6n, las palabras de apertura, a cargo del doctor Roberto Jaramillo Uricoechea, destacaron la evoluci6n de la instrumentaci6nquirurgica, a partir del nacimiento de la esc uela tecnica de instrumentaci6 $\mathrm{n}$, que dio paso a la formaci6n de tecn6logas y luego de instrumentadoras profesionales.

Es importante resaltar la participaci6n de las docentes de la Facultad de Instrumentaci6n Quirúrgica y los especialistas del Hospital de San José en la organización del mencionado acto académico. Además, este evento fue la oportunidad para resaltar la importante labor realizada por la fundadora del pro- grama de lnstrumentaci6n Quirúrgica y sus sucesoras, por lo que se rindi6 un merecido homenaje a Celmira Acevedo de Segura, fundadora de la facultad de lnstrumentaci6n Quirúrgica en el ailo de 1951 ya las exdecanas: Lucia Rivadeneira (1972-1973),
Alicia Ballesteros de Duarte (1 973- 1996), Leticia Rodriguez Ramírez (1997-2000) y Jeannette Neira González (2000), así como un homenaje p6stumo en memoria de Carmen Ramírez (1 955-1966) e Isabel Días Pulido (1967-1971).

Durante este acto, la facultad de Instrumentaci6n Quirúrgica fue condecorada con la "Orden del Congreso de Colombia en el grado de cruz de! comendador", otorgada por el Congreso de la Republica a aquellas entidades que por su carácter han sido baluartes del progreso de la comunidad, en beneficio del desarrollo del país. Esta condecoraci6n fue impuesta por la Honorable senadora María Cleofe Martínez, en representaci6n de la mesa directiva del Senado de la Republica

De igual modo, el 8 de noviembre de 2001 en acto realizado en el Auditorio Guillermo Fergusson del Hospital de San José, el Concejo de Bogotá impuso la orden civil al mérito "José Acevedo y Gómez" en el grado de Gran Cruz, a la facultad de Instrumentaci6n, en reconocimiento a las labores realizadas por la misma desde su fundaci6n; dicha condecoraci6n fue impuesta por el Honorable Concejal Collin Crawford.

Estos reconocimientos son una muestra de la gran labor que ha venido realizando la facultad de instrumentación $y$ por esto nos sentimos orgullosos de celebrar los primeros cincuenta años.

Marfa Elizabeth Matamoros Velasquez

Decana, Facultad de Instrumentación 